\title{
Educação 4.0: um Estudo de Caso com Atividades de Computação Desplugada na Amazônia Brasileira
}

\author{
Deivid Eive Silva \\ Departamento de Informática \\ Universidade Federal do Paraná \\ Curitiba, PR, Brasil \\ dessilva@inf.ufpr.br
}

\author{
Marialina Corrêa Sobrinho \\ Universidade Federal do Oeste \\ do Pará \\ Santarém, PA, Brasil \\ linasobrinho@gmail.com
}

\author{
Natasha Malveira Valentim \\ Departamento de Informática \\ Universidade Federal do Paraná \\ Curitiba, PR, Brasil \\ natasha@inf.ufpr.br
}

\begin{abstract}
This case study aimed to cultivate 21st Century competences and skills related to Education 4.0, such as problem-solving, collaboration and autonomy. To this end, unplugged computing activities were performed with 25 students from four rural schools located in Tapajós-Arapiúns (Brazilian Amazon). As part of the methodology, a maze based on Google's Blockly Games tool was produced, inspired by hopscotch, a popular joke among children. After this case study, a qualitative analysis was performed, and it indicates that Unplugged Computing activities instigate students' skills and competences, as autonomy, communication and teamwork. Besides, this methodology proves to be useful for disseminating Education 4.0 concepts, due to its ease of application and low cost, especially in distant places with few resources.
\end{abstract}

\section{KEYWORDS}

Educação 4.0, Competências e Habilidades, Computação Desplugada, Século XXI

\section{INTRODUÇÃO}

0 processo de digitalização e automatização da Indústria provocou mudanças significativas na sociedade, incluindo a Educação. Nesse sentido, percebeu-se a necessidade de uma formação educacional mais alinhada ao mundo contemporâneo que prepare os jovens para os desafios do Século XXI, como lidar com os recursos e os processos tecnológicos. Além disso, é indicado que a escola desenvolva nos estudantes competências e habilidades que são requeridas no Século XXI, tais como: criatividade, inovação e autonomia. Desse modo, acredita-se que será possível transformar os jovens em sujeitos autônomos, criativos e participativos, e consequentemente, profissionais mais aptos para trabalhar em uma indústria transformadora. Este é um novo parâmetro que redefine o formato de educação, conhecida como Educação 4.0 [22], [9], [1].

As competências são entendidas como a capacidade de alcançar os objetivos propostos por meio de recursos cognitivos (saberes, técnicas e atitudes). Assim, as competências podem ser definidas como uma combinação de conhecimentos, experiências e habilidades. Portanto, as competências referem-se à realização de um tipo de tarefa que só pode ser alcançada a partir das habilidades dos alunos. Nesse sentido, as habilidades são reconhecidas como uma capacidade aprendida por meio de atividades práticas [19], [1]. Por exemplo, se o professor tiver o objetivo de desenvolver competências da Matemática nos alunos, precisa-se desenvolver habilidades numéricas, como conceitos sobre número, quantidade, agrupamentos, dentre outros conteúdos da Matemática, como apresentado na Base Nacional Comum Curricular - BNCC (documento que regulamenta o que deve ser trabalhado em sala de aula) [18], [6].

As competências e habilidades do século XXI consistem em liderança, colaboração, criatividade, inovação, comunicação eficaz, inteligência emocional, empreendedorismo, resolução de problemas, trabalho em equipe, dentre outras. Estas habilidades são consideradas importantes para a vida no Século XXI e inovadoras para viver na era da Educação 4.0 [17]. Para atender a carência de recursos humanos qualificados e atuar nesse novo conceito de mercado, a Educação 4.0 sugere práticas em sala de aula com o uso de tecnologias diversas, como: linguagem de programação, robótica, gamificação, inteligência artificial, dentre outras. 0 uso desses recursos ajuda desenvolver as competências e habilidades nos estudantes. Além disso, as metodologias ativas de aprendizagem, como aprendizagem baseada em problemas e aprendizagem colaborativa permitem trabalhar o protagonismo do estudante [15].

Este trabalho apresenta um estudo de caso que teve o objetivo de cultivar competências e habilidades do Século XXI, a partir de atividades de Computação Desplugada com 25 estudantes de 4 escolas da região do Tapajós-Arapiúns, localizada nas proximidades da cidade de Santarém-PA. Desse modo, foi produzido um labirinto baseado no Blockly Games da Google e inspirado na Amarelinha (uma brincadeira popular entre crianças). Esta atividade teve a Matemática como disciplina de Apoio. Os resultados deste estudo de caso mostram que os estudantes podem melhorar competências e habilidades relacionadas à Educação 4.0. 
Este trabalho está organizado em 7 Seções. A Seção 2 aborda alguns aspectos da Educação 4.0 e apresenta alguns trabalhos relacionados à Computação Desplugada. A Seção 3 descreve o planejamento e execução do estudo de caso. A Seção 4 apresenta os resultados quantitativos acerca dos desafios matemáticos. A Seção 5 descreve e discute os resultados qualitativos alcançados. A Seção 6 trata das ameaças a validade. Finalmente, as conclusões e trabalhos futuros são apresentados na Seção 7.

\section{BACKGROUND}

O termo Educação 4.0 ainda é considerado recente. Dessa maneira, há pouca literatura escrita, incluindo estudos empíricos que focam no uso das tecnologias para desenvolver competências e habilidades do Século XXI [3]. Uma primeira menção para a Educação 4.0 foi dada por [23], sendo um modelo de aprendizagem que atende as necessidades da Indústria 4.0 (conhecida também como quarta revolução industrial).

Nesse sentido, é importante entender como a educação foi sendo constituída ao longo do tempo. A Educação 1.0 (primeira revolução industrial) foi marcada pela relação estreita entre professores e alunos, onde havia uma falta de padronização do currículo e se concentrava apenas na capacidade de ler, escrever e calcular. Na Educação 2.0 (segunda revolução industrial), exigiu-se que os trabalhadores soubessem ler e escrever. Esse pré-requisito provocou a necessidade de treinar pessoas para atuar na linha de produção. Além disso, passou-se a incluir os livros didáticos, houve tendência para as áreas de filosofia e ciência, surgimento dos métodos indutivos e empíricos, melhora nos métodos de ensino e universidade com foco na pesquisa Posteriormente, com a chegada do computador, o conceito de Educação 2.0 mudou para Educação 3.0 (terceira revolução industrial). Desse modo, o recurso tecnológico passou a servir de suporte nos processos de ensino e aprendizagem. Por conseguinte, com a quarta Revolução Industrial, a educação ainda não conseguiu ser atualizada. De fato, a tecnologia permite os alunos participarem de cursos à distância e ter acesso as fontes ilimitadas de informação. No entanto, o ensino e a abordagem de aprendizagem não mudaram, os métodos de aprendizagem ainda estão de acordo com os critérios da Educação 2.0 [14].

Diante disso, foram apresentadas 7 facetas para configurar uma sala de aula para uma Educação 4.0, sendo: (1) Personalização: material didático preparado para atender diferentes tipos de aprendizagem, como livro interativo e vídeo interativo; (2) Gamificação: elementos lúdicos para ajudar na motivação; (3) Sistema Gerenciador de Aprendizagem: atividades práticas e acesso a modulos de aprendizagem; (4) Adaptabilidade: atividades adaptadas conforme o conhecimento e a aprendizagem do estudante; (5) Programas de Suporte: métodos de análise para encontrar alunos com diculdades; (6) Sistema de Perguntas e Respostas Inteligentes: teletutores inteligentes para apoiar os alunos; e (7) EAvaliação: correção de trabalho automaticamente através de sistema . Estas facetas podem contribuir para o protagonismo do estudante, dinamizar os processos de ensino e aprendizagem e colaborar para a formação de competências necessárias para a vida no Século XXI [7].

$\mathrm{Na}$ literatura há distintas classificações para as competências e habilidades. Estas podem ser: Organizacionais (gerenciar tempo, liderança e planejamento), Comunicativas (negociação e comunicação), Comportamentais (iniciativa, criatividade, ética e coerência), Cognitivas (solução de problemas, pensamento crítico, agilidade para tomar decisões, planejamento, interpretação, reflexão, generalização, pensamento abstrato e empreendedorismo) e Socioemocionais (relacionamento interpessoal, trabalho em equipe, gerência de interesses, consciência ambiental, autoconfiança, autodesenvolvimento, integridade, persuasão, autocontrole das emoções, empatia, flexibilidade, estabilidade emocional, colaboração, paciência, entusiasmo, resiliência e otimismo) [11], [21], [18].

Os estudantes do Século XXI necessitam cada vez mais desenvolver essas competências e habilidades, a fim de lidar com um ambiente tecnológico em mudança [20]. Desse modo, acredita-se que o ensino da Computação pode contribuir para o desenvolvimento de habilidades relacionadas à construção do pensamento de maneira lógica, possibilitar o ensino da matemática mais lúdico para um maior número de estudantes, além de estimular capacidades cognitivas [2]. Nesse artigo relata-se atividades realizadas com Computação Desplugada, definida na seção a seguir.

\subsection{Trabalhos Relacionados}

Um dos estudos mais conhecido sobre Computação Desplugada é referente as atividades desenvolvidas por Bell e Witten [5], que consistem no uso dos princípios da Ciência da Computação sem a necessidade da utilização dos computadores. Esta metodologia de trabalho desperta interesse de pesquisadores e professores em diversos países e a sua divulgação está sendo feita através do site (http://www.csunplugged.org/) [10]. Além disso, como uma forma de fomentar o ensino da computação, disponibilizou-se na internet uma versão traduzida do livro ${ }^{1}$ sobre Computação Desplugada [4]. Este livro dispõe de atividades lúdicas que podem ser implementadas por professores, inclusive os da Educação

\footnotetext{
1https://classic.csunplugged.org/wp-

content/uploads/2014/12/CSUnpluggedTeachers-portuguese-brazil-feb2011.pdf
} 
Básica. Na literatura foram identificados alguns relatos de experiência sobre o uso da Computação Desplugada. A seguir serão listados 3: (1) aplicação de gincana com estudantes do Ensino Fundamental para ensinar fundamentos da computação [10]; (2) trabalho de extensão com estudantes do Ensino Médio para estabelecer diálogo na escola sobre a Ciência da Computação e as suas profissões [23] e (3) integração do pensamento computacional com os conteúdos curriculares da Educação Básica [12]. Desse modo, percebe-se que a Computação Desplugada pode ser aplicada de diversas maneiras e em diferentes contextos.

Devido a sua facilidade de aplicação, as atividades de Computação Desplugada se tornam viáveis em lugares longínquos ou de pouca infraestrutura [23]. Portanto, a Computação Desplugada demonstrou ter um potencial para este estudo de caso. Para este estudo de caso foi escolhida a faceta Personalização (criação de material didático preparado para atender diferentes tipos de aprendizagem) proposta por [7]. A partir do conceito de Computação Desplugada, desenvolveu-se um labirinto impresso com a finalidade de apoiar os estudantes no desenvolvimento de competências e habilidades do Século XXI.

\section{ESTUDO DE CASO}

0 estudo de caso foi realizado com 25 estudantes do Ensino Fundamental, de 4 escolas da zona rural da região do TapajósArapiúns, localizada próximo da cidade de Santarém-PA. Os participantes foram organizados em 5 grupos de 5 alunos. Como as turmas são pequenas nas escolas do interior, os estudantes foram agrupados da seguinte forma: $4^{\circ}$ e e 5o ano (1 equipe pela manhã e outra à tarde), $6^{\circ}$ e $7^{\circ}$ ano ( 1 equipe pela manhã e outra à tarde) e $8^{\circ}$ e $9^{\circ}$ ano (1 equipe pela manhã). Optou-se por este agrupamento devido aos tipos de questões que foram entregues em cada grupo. Portanto, os times deveriam percorrer um labirinto impresso usando a lógica de programação. Além disso, os estudantes precisavam responder 4 desafios de lógica matemática que estava contido no labirinto disposto. Desse modo, 15 estudantes participaram das atividades pela parte da manhã, enquanto 10 participaram no turno da tarde.

Este estudo de caso teve como objetivo desenvolver a lógica e resolução de problemas por meio da Computação Desplugada. Para isso, utilizou-se a Matemática como disciplina de apoio. Para a organização deste estudo de caso, foram utilizados os passos do processo experimental proposto por [16], sendo dividido em planejamento, execução e análise.

\subsection{Planejamento do Estudo de Caso}

Com a finalidade de verificar os benefícios da Computação Desplugada para a Educação 4.0, o estudo de caso foi dividido em 2 partes: implementação e avaliação. Na primeira parte, os pesquisadores conversaram sobre a necessidade de realizar um estudo sobre competências e habilidades do Século XXI como resolução de problemas. Desse modo, escolheu-se um local apropriado para receber os estudantes das 4 escolas. Este local é um centro que comumente atende a população ribeirinha e desenvolve trabalhos com estas comunidades, incluindo projetos sociais.

Para a implementação do estudo de caso, foram selecionados alguns desafios matemáticos para incentivar a resolução de problemas. Além disso, produziu-se um labirinto inspirando na ferramenta Blockly Games da Google 2 para se trabalhar a lógica de programação e a resolução de problemas. Portanto, foram preparados kits com materiais de apoio para os grupos. Os kits continham: lápis e borracha, fita adesiva, labirinto impresso composta por duas folhas A4 e setas de direção (para frente, para trás, vire à direita e vire à esquerda), como visto na Figura 1.

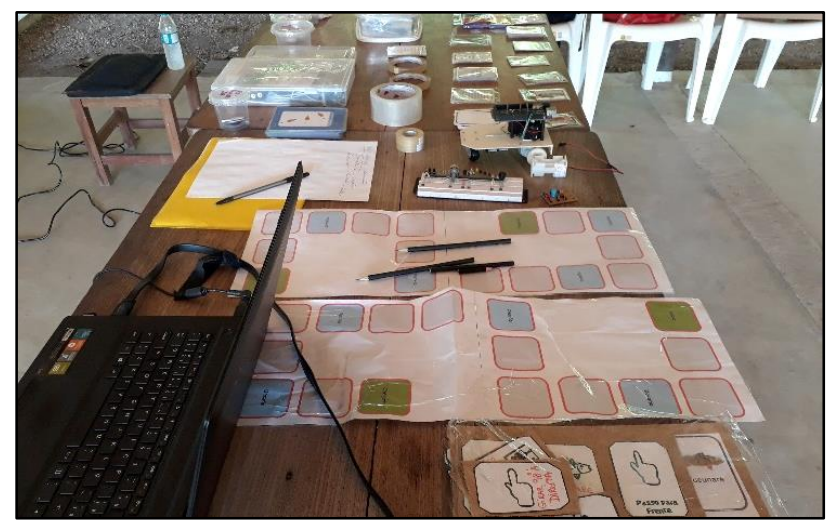

Figura 1. Materiais usados na atividade de Computação Desplugada

Na segunda parte, definiu-se o processo de avaliação das percepções dos estudantes acerca da atividade desenvolvida. Para a coleta de dados utilizou-se Grupo Focal, onde os estudantes em grupos relataram sobre a contribuição da atividade para a sua aprendizagem. Grupo Focal é uma técnica qualitativa usada para coletar dados por meio de entrevistas em grupo, organizadas para discutir um determinado objeto, como uma tecnologia [13]. Para a análise qualitativa dos dados, obtidos na $2^{a}$ parte deste estudo de caso, utilizou-se a ferramenta Atlas.ti versão 6, seguindo o método Grounded Theory [25].

\subsection{Execução do Estudo de Caso}

Primeiramente, o pesquisador apresentou o projeto aos participantes. Posteriormente, os estudantes foram organizados em grupos. Para a atividade, cada grupo recebeu

2 https://blockly-games.appspot.com/ 
em sua mesa um material de apoio. Além disso, foi entregue o labirinto composto de ponto de partida e chegada, e 4 desafios de lógica matemática. Esses desafios foram sorteados de acordo com o nível de escolaridade dos participantes. Dessa maneira, por meio de um trabalho em equipe, os alunos tinham que decidir o melhor caminho a percorrer o labirinto usando a lógica de programação, além de resolver os problemas corretamente no tempo estipulado de 30 minutos, como visto na Figura 2.

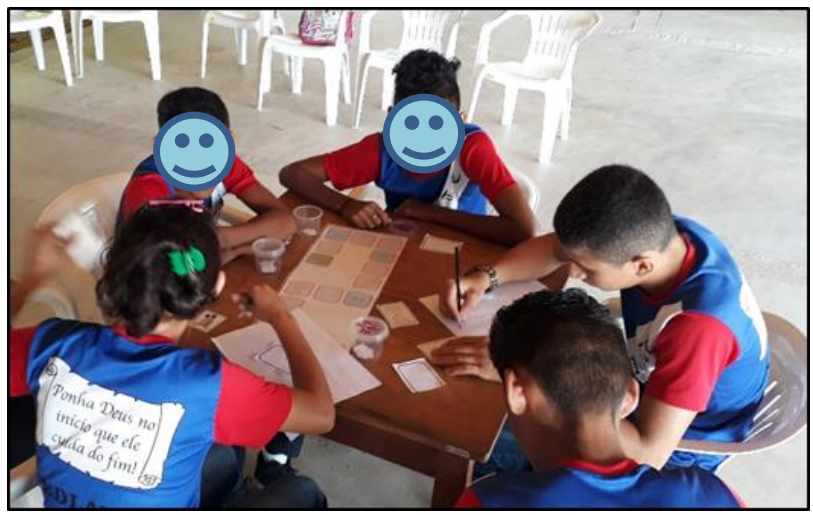

Figura 2. Realização da Atividade de Computação Desplugada com estudantes

Após findar esse tempo, o pesquisador se direcionou a cada equipe para conferir as respostas e, em alguns casos, ajudar a entender o problema restante. Os grupos conseguiram resolver 3 desafios corretamente, porém nenhum grupo acertou os 4 . Para finalizar o estudo, utilizou-se um labirinto no tamanho de um banner $(80 \times 120 \mathrm{~cm})$ que foi posto ao chão. Portanto, os grupos puderam demonstrar o pensamento construído para percorrer o labirinto. Para isso, utilizou-se as fichas de comando, como: para frente, para trás, vire à esquerda e vire à direita.

Por conseguinte, os estudantes conseguiram compartilhar o conhecimento construído com os demais grupos de colegas e professores presentes. Finalmente, os participantes relataram as suas experiências, esboçaram as suas dificuldades e contaram suas impressões acerca da atividade com Computação Desplugada, a partir da disciplina Matemática.

\section{RESULTADOS QUANTITATIVOS}

As figuras 3, 4 e 5 apresentam os desafios matemáticos que foram propostos para as equipes do $4^{\circ}$ e $5^{\circ}$ ano, 6ํㅡ e 7ㅇao a e 8o e 9o ano, a fim de incentivar habilidades cognitivas como raciocínio matemático e lógico. Estes desafios foram revisados por professores de matemática desses níveis de ensino.

\begin{tabular}{|c|c|}
\hline \multicolumn{2}{|c|}{40 e 50 ano } \\
\hline $\begin{array}{l}\text { Para uma receita, Ana precisa } \\
\text { de } 1 \mathrm{~kg} \text { de surumbi, mas só } \\
\text { tem } 625 \mathrm{~g} \text {. De quantas gramas } \\
\text { ela ainda precisa para } \\
\mathbf{1} \text { completar } 1 \mathrm{~kg} \text { ? }\end{array}$ & $\begin{array}{l}\text { Marta quer comprar uma mala } \\
\text { que custa } \mathrm{R} \$ 184,99 . \text { Ela tem } \\
\mathrm{R} \$ 95,00 \text {. Quanto Ihe falta para } \\
\text { conseguir comprar essa mala? }\end{array}$ \\
\hline $\begin{array}{l}\text { Maria tem } 10 \text { jambos, João } \\
\text { tem } 2 \text { a menos que Maria, } \\
\text { Pedro tem } 4 \text { a menos que } \\
\text { Maria, Antônio tem } 7 \text { a menos } \\
\text { que João. Quantos jambos } \\
3 \text { Antônio tem? }\end{array}$ & $\begin{array}{l}\text { Qual o sucessor de } \\
\qquad\left(9^{*} 4\right)-6 ?\end{array}$ \\
\hline
\end{tabular}

Figura 3. Desafios propostos paras as 2 equipes do $4^{\circ}$ e $5^{\circ}$ ano

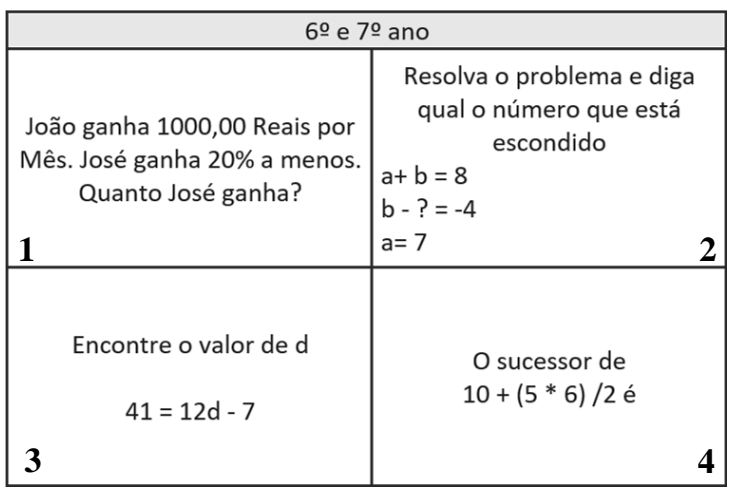

Figura 4. Desafios propostos paras as 2 equipes do 6으 e 7ํㅡㄴ ano

\begin{tabular}{|c|c|}
\hline \multicolumn{2}{|c|}{ 8 e 9 ano } \\
\hline $\begin{array}{c}\text { Represente } 943 \text { milhões em } \\
\text { notação científica }\end{array}$ & $\begin{array}{l}\text { Calcule o valor de x no } \\
\text { triângulo abaixo: }\end{array}$ \\
\hline 1 & 2 \\
\hline $\begin{array}{l}\text { Qual o valor da medida do } \\
\text { ângulo? }\end{array}$ & $\begin{array}{l}\text { O perímetro de um retângulo } \\
\text { é } 48 \mathrm{~cm} \text {. A medida do lado } \\
\text { maior é o triplo da medida do } \\
\text { lado menor. Qual a área } \\
\text { deste retângulo, em } \mathrm{cm}^{2} \text { ? }\end{array}$ \\
\hline
\end{tabular}

Figura 5. Desafios propostos para a equipe do 8 e 9o ano

0 quadro 1 apresenta os desafios conquistados pelos estudantes durante a atividade de Computação Desplugada, relacionando a quantidade de assertivas com os números de equipes participantes. 
XI Computer on the Beach

\begin{tabular}{|c|c|c|c|c|}
\hline & $\begin{array}{c}\text { Desafio } \\
1\end{array}$ & $\begin{array}{c}\text { Desafio } \\
2\end{array}$ & $\begin{array}{c}\text { Desafio } \\
3\end{array}$ & $\begin{array}{c}\text { Desafio } \\
4\end{array}$ \\
\hline $\begin{array}{c}\text { Equipe } 1 \\
\text { (4으 e 5o ano) }\end{array}$ & $x$ & $\mathrm{X}$ & & $\mathrm{x}$ \\
\hline $\begin{array}{c}\text { Equipe } 2 \\
\text { (4o e 5ao) }\end{array}$ & $x$ & & $x$ & $\mathrm{x}$ \\
\hline $\begin{array}{c}\text { Equipe } 3 \\
\text { (6을 } 7^{\circ} \text { ano) }\end{array}$ & $\mathrm{x}$ & $\mathrm{X}$ & $\mathrm{x}$ & \\
\hline 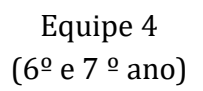 & $\mathrm{x}$ & $\mathrm{x}$ & & $\mathrm{x}$ \\
\hline $\begin{array}{c}\text { Equipe } 5\left(8^{\circ} \mathrm{e}\right. \\
90 \text { ano) }\end{array}$ & $\mathrm{x}$ & $\mathrm{x}$ & $x$ & \\
\hline
\end{tabular}

\section{Quadro 1: Desafios conquistados pelos estudantes}

Em seguida, é apresentada a análise qualitativa dos dados a partir dos feedbacks dos participantes sobre a atividade realizada.

\section{RESULTADOS QUALITATIVOS E DISCUSSÕES}

Neste estudo de caso adotou-se o método Grounded Theory (GT) para análise qualitativa. Portanto, os comentários dos participantes foram analisados por meio de um subconjunto das fases de codificação sugerido por [25], sendo a codificação aberta (1 1 a fase do método GT) e axial ( 2 a fase do GT). Neste estudo de caso, não se fez necessário a codificação seletiva ( $3^{\mathrm{a}}$ fase do GT), pois foi possível obter a resposta do estudo de caso com a execução das etapas de codificação aberta e axial [8].

A análise foi realizada da seguinte forma: na primeira etapa do GT (codificação aberta), os códigos foram criados (conceitos para entender os benefícios da atividade de Computação Desplugada) de acordo com o feedback dos participantes. Posteriormente, os códigos foram agrupados conforme as suas propriedades, formando conceitos que representam categorias. Finalmente, estes códigos foram relacionados uns com os outros (codificação axial).

O objetivo da análise qualitativa nesse estudo foi entender como a Computação Desplugada contribuiu para o desenvolvimento das competências e habilidades do Século XXI, como a capacidade de pensar de forma lógica e sistemática, resolver problemas, dentre outras habilidades ligadas à Educação 4.0.

A. Contribuição da Computação Desplugada no desenvolvimento das competências e habilidades do Século XXI.

Alguns participantes disseram que a Computação Desplugada incentiva o trabalho em equipe (veja a citação Q01 abaixo). Outros notaram que a Computação Desplugada estimula a resolução de problemas (veja a citação Q02). Além disso, alguns participantes acreditam que a habilidade de liderar ajuda na organização do grupo para a execução das tarefas (veja a citação Q04).

"Faltou na gente a união, saber trabalhar junto. Trabalhar em equipe é bom. Nós éramos 5 pessoas, mas apenas dois trabalhavam" (Q01).

"Eu tive que resolver alguns problemas. Eu e meus colegas conseguimos resolver três desses desafios" (Q02).

"Acho que faltou um líder para organizar a nossa equipe. Nós já tínhamos visto o conteúdo para responder à pergunta. Mas, o nervosismo atrapalhou um pouco" (Q04).

Os relatos mostram que os participantes reconheceram a importância das competências para a sua formação escolar. Nesse sentido, os estudantes afirmam que uma habilidade pode contribuir como surgimento de outra. Por exemplo, sentiu-se a necessidade da competência liderança para gerenciar o tempo, dividir as tarefas e organizar o grupo. Consequentemente, pela falta da figura de um líder, alguns estudantes ficaram inseguros e poucos trabalharam. Entretanto, a atividade permitiu com que os participantes se atentassem para uma maior comunicação, colaboração e organização para a realização das tarefas. A partir disso, acredita-se que os alunos conseguirão trabalhar melhor em futuras atividades, tendo em vista que entenderam a importância dessas competências e habilidades para a sua aprendizagem.

B. Dificuldades encontradas na atividade com Computação Desplugada.

Alguns participantes afirmam que sentiram dificuldades com a Matemática (veja a citação Q05). Em adição, outros participantes contam que as dificuldades estavam na interpretação dos problemas (veja citação a Q06). Em sequência, alguns participantes relatam que houve dificuldades no uso dos comandos de direção para programar o labirinto (veja a citação Q07 abaixo). Por fim, alguns participantes contam que alguns problemas não foram resolvidos (veja a citação Q08 abaixo).

"Nosso grupo teve bastante dificuldade na Matemática. A gente tinha que pensar até achar o resultado. A atividade mexeu com o nosso cérebro, mexeu com a cabeça da gente com coisa que nem sabíamos mais" (Q05).

"[...] Nós sentimos um pouco de dificuldade para entender os problemas. Mas, nós já tínhamos visto o conteúdo para responder à pergunta" (Q06).

"Foi à primeira vez que fizemos algo assim. Nós sentimos um pouco de dificuldade de colocar os comandos corretamente para percorrer no labirinto" (Q07).

"Eu consegui resolver alguns problemas. Eu e meus colegas conseguimos resolver três desses desafios" (Q08).

Os depoimentos mostram que os estudantes sentiram dificuldades em problemas matemáticos que já haviam estudado em sala de aula. Nesse contexto, acredita-se que o 
desempenho acadêmico poderá ser melhorado com atividades que incentivam o desenvolvimento das competências e habilidades do Século XXI. Desse modo, poderá ser melhorado aspectos cognitivos, como raciocínio lógico e matemático, além de aspectos não-cognitivos, como colaboração e comunicação. De modo geral, foi percebido que os alunos se apresentaram positivos mesmo diante de algumas dificuldades.

C. Motivação dos alunos na atividade com Computação Desplugada.

Alguns participantes afirmam que a Computação Desplugada foi uma forma divertida de aprender (veja a citação Q09 abaixo). Outros participantes, contam que gostariam de fazer Computação Desplugada com outras disciplinas, além da Matemática (veja a citação Q10 abaixo). Em adição, alguns participantes afirmam que foi uma atividade diferenciada (veja a citação Q11 abaixo). Em sequência, alguns participantes disseram que gostaram de usar o labirinto para trabalhar a Computação Desplugada (veja a citação Q12 abaixo).

"Eu achei divertida a atividade com o labirinto. Eu achei uma forma diferente de aprender. Eu nunca tinha feito uma atividade assim" (Q09).

"Eu gostaria que a atividade fosse aplicada em outras disciplinas, tipo português, artes, geografia, ciências [...]" (Q10).

"É a primeira que vez que faço algo assim, a minha professora não faz isso em sala de aula. A gente gostou, parece uma amarelinha, conseguimos aprender e nos divertir também" (Q11).

"Eu gostei da atividade com o labirinto. Eu achei uma forma diferente de aprender" (Q12).

Os comentários mostram que foi possível cultivar competências e habilidades do Século XXI. Os depoimentos indicam que a proposta é interessante para os estudantes da região do Tapajós-Arapiúns, principalmente pelo fato de ser fácil a sua replicação. Além disso, a atividade com Computação Desplugada conseguiu incentivar habilidades, como pensamento computacional, dentre outras habilidades, mesmo sem o uso do computador. Desse modo, a atividade se apresenta como uma alternativa a mais a favor de uma Educação 4.0.

Os estudantes conseguiram compartilhar o conhecimento construído com os demais grupos de colegas e professores presentes. Finalmente, os participantes relataram as suas experiências, esboçaram as suas dificuldades e contaram suas impressões acerca da atividade de Computação Desplugada.

\section{AVALIAÇÃO DAS AMEAÇAS À VALIDADE}

Como em todos os estudos, existem também ameaças que podem afetar a validade dos resultados. Nesse trabalho, foram categorizadas as ameaças conforme a abordagem de [26].
Dentre essas ameaças, foram identificadas as do tipo interna e externa. Desse modo, buscou-se amenizá-las durante a condução do estudo de caso para diminuir os possíveis riscos.

Assim, para a validade interna foram consideradas três ameaças principais que poderiam representar um risco para uma interpretação indevida dos resultados, tais como: (a) efeitos de treinamentos: não foi realizada nenhum tipo de capacitação, apenas dada instruções. Esta atividade foi um dos primeiros contatos dos estudantes com o pensamento computacional; (b) experiência em classificação: os grupos foram organizados conforme o nível de ensino; e (c): tempo de medição: os estudantes tiveram o mesmo tempo para começar e terminar as atividades.

Para a Validade Externa, foram consideradas duas ameaças: (a) grupos com estudantes de turmas distintas: não houve grandes diferenças entre os estudantes, pois todos já haviam estudados os conteúdos trabalhados e conseguiram revisar simultaneamente os conteúdos, além de trabalharem juntos o pensamento computacional; e (b) o estudo realizado fora da escola: a atividade foi realizada em um espaço de fácil acesso e que geralmente dispõe de atividades diversificadas para as comunidades. Além disso, para este projeto foi disponibilizado aos estudantes e professores todas as condições necessárias para participarem das atividades, como transporte e alimentação.

\section{CONSIDERAÇÕES FINAIS E TRABALHOS FUTUROS}

Este trabalho apresentou um estudo de caso que teve o objetivo de cultivar competências e habilidades do Século XXI, a partir de atividades de Computação Desplugada. Desse modo, foi utilizado um labirinto baseado no Blockly Games da Google e inspirado na brincadeira popular Amarelinha. Esta atividade teve a Matemática como disciplina de Apoio. Os resultados deste estudo de caso mostram que os estudantes podem reforçar o conteúdo curricular, além de treinar competências e habilidades do Século XXI.

Com a análise qualitativa deste estudo de caso, foi possível perceber que os estudantes trabalharam bem a resolução de problemas, além de reconhecer a importância de habilidades como autonomia, comunicação e trabalho em equipe. Desse modo, acredita-se que os estudantes conseguirão trabalhar melhor em atividades futuras, uma vez que reconheceram o significado das competências para a sua aprendizagem. Além disso, os professores presentes poderão trabalhar com base nisso em novas propostas em sala de aula, a fim de preparar os seus alunos para os desafios do Século XXI.

Com base nos depoimentos, é possível dizer que a Computação Desplugada é uma atividade interessante para os estudantes da zona rural, principalmente pelo fato de ser fácil 
a sua replicação nas escolas. Uma das características da Computação Desplugada é a sua facilidade de aplicação, fazendo com que atividades com pensamento computacional se tornem viáveis em lugares distantes e/ou de pouca infraestrutura. Dessa forma, a Computação Desplugada pode colaborar na disseminação de conceitos e práticas da Educação 4.0 nas comunidades da Amazônia.

Entretanto, a maioria das escolas brasileiras segue o currículo tradicional de ensino e as datas estipuladas em seus calendários acadêmicos. Nesse sentido, isso pode ser visto como uma barreira para o professor introduzir práticas de Computação Desplugada em suas propostas pedagógicas. No entanto, por meio deste estudo de caso, pode-se observar que é possível unir conteúdo educacional com Computação Desplugada. Além disso, esta atividade poder ser desenvolvida com materiais de baixo custo como papelão, folhas de papel, lápis e borracha.

Com esta iniciativa, espera-se abrir novos caminhos para outros projetos no formato de Educação 4.0 em parceria com professores de escolas de outras comunidades, com atividades que envolvam conceitos de gamificaçao, robótica com materiais recicláveis, dentre outros. Desse modo, acredita-se que será possível melhorar o ensino e a aprendizagem dos estudantes da zona rural, além de provocar mudanças positivas no cenário educacional brasileiro.

\section{AGRADECIMENTOS}

Esta publicaçao foi escrita com apoio financeiro do $\mathrm{CNPq}$ (Conselho Nacional Brasileiro de Desenvolvimento Cientı fico e Tecnologico).

\section{REFERÊNCIAS}

[1] Angrisani, L.; Arpaia, P.; Capaldo, G.; Moccaldi, N.; Salatino, P.; Ventre, G. (2018) Academic Fablab at University of Naples Federico II: New Research and Development Opportunities in the Fileds of IoT and Industry 4.0. Journal of Physics: Conference Series, v. 1065, 2018.

[2] Aono, A. H., Silva, H. R. V., Musa, D. L., Pereira, V. A., Almeida, J. G. (2017). A Utilização do Scratch como Ferramenta no Ensino de Pensamento Computacional para Crianças. In: Workshop sobre Educação em Computação, 2017, São Paulo. Anais do CSBC, 2017.

[3] Ayub, E., Wei, G. W., Luaran, J. E., \& Leong, L. C. (2018). An Exploratory Study of a Framework for Designing and Developing a Massive Online Course as Smart Future Classroom in VLE. Proceedings of the 2nd International Conference on E-Education, EBusiness and E-Technology (pp. 57-62). ACM.

[4] Bell, T., Witten, I. H., Fellows, M., Adams, R., \& McKenzie, J. (2011). Ensinando Ciência da Computação sem o uso do computador. Computer Science Unplugged ORG.

[5] Bell, T. C. G.; Witten, I. (1995). Computer Science Unplugged: Capturing the interest of the uninterested. Anais do NZ Computer Conference, Wellington, Nova Zelândia.

[6] BNCC. Base Nacional Comum Curricular, 2018. Brasília: MEC. Disponível em: <http://download.basenacionalcomum.mec.gov.br/>. Acesso em: 15 mar. 2019.

[7] Ciolacu, M.; Tehrani, A.; Beer, R.; Popp, H. Education 4.0 - Fostering Student Performance with Machine Learning Methods. Proceedings of IEEE 23rd
International Symposium Design and Technology of Electronics Packages (SIITME), p. 438-443, 2017.

[8] Conte, T.; Cabral, R.; Travassos, G.H.; Aplicando Grounded Theory na Análise Qualitativa de um Estudo de Observação em Engenharia de Software - Um Relato de Experiência". In: V WOSES 2009, v. 1, p. 26 - 37, 2009.

[9] Coskun, S., Gencay, E., Kayikci, Y. (2016) Adapting Engineering Education to Industrie 4.0 Vision, 16th Production Research Symposium, 2016.

[10] Costa, T. R., Batista, A., Maia, M., Almeida, L. e Farias, A. (2012) “Trabalhando Fundamentos de Computação no Nível Fundamental: experiência de licenciandos em Computação da Universidade Federal da Paraíba". XX Workshop de Educação em Computação. Curitiba, Brasil.

[11] Cotet, G. B.; Balgiu, B. A.; Negrea, V. (2017) Assessment procedure for the soft skills requested by Industry 4.0. In MATEC Web of Conferences, v. 121, 2017.

[12] Ferreira, A. C., Melhor, A., Barreto, J., de Paiva, L. F., \& Matos, E. (2015). Experiência Prática Interdisciplinar do Raciocínio Computacional em Atividades de Computação Desplugada na Educação Básica. In: Anais do XXI Workshop de Informática na Escola, pp. 256.

[13] Grigoreanu, V., Fernandez, R., Inkpen, K., Robertson, G. (2009). What Designers Want: Needs of Interactive Application Designers. In IEEE Symposium on Visual Languages and Human-Centric Computing, pp. 139146.

[14] Hartono, S., Kosala, R., Supangkat, S. H., Ranti, B. (2018). Smart Hybrid Learning Framework Based on Three-Layer Architecture to Bolster Up Education 4.0. In 2018 International Conference on ICT for Smart Society (ICISS), p. 1-5, 2018.

[15] Jumari, N. F.; Mohd-Yusof, K.; Phang, F. A. Metacognitive development in engineering students through cooperative problem-based learning (CPBL) Advances in Intelligent Systems and Computing, n. 627, p. 107-120, 2018.

[16] Lazar, J., Feng, J. H., e Hochheiser, H. (2010). Research Methods in HumanComputer Interaction. John Wiley and Sons, 1st edition.

[17] Messias, G.; Rodrigues, U.; Braga, L., Nakamura, W., Ferreira, B.; Paiva, A.; Valentim, N. Education 4.0 and 21st Century Skills: A Case Study with Robotics Activities in Classroom. In: XXIX Brazilian Symposium on Computers in Education, 2018. p. 715-724.

[18] Mourtzis, D. Development of Skills and Competences in Manufacturing Towards Education 4.0: A Teaching Factory Approach. In J. Ni et al. (Eds.): AMP 2018, LNME, p. 194-210, 2018.

[19] Perrenoud, P. Construir as Competências desde a Escola (1999), Porto Alegre, Artmed Editora.

[20] Pérez-Pérez, M., Gómez, E., Sebastián, M. (2018) Delphi Prospection on Additive Manufacturing in 2030: Implications for Education and Employment in Spain, in Journal Materials, DOI: 10.3390/ma11091500, 2018, pp. 1500.

[21] Piñol, T.C.; Artigas, S.; Rodríguez, M. C.; Minguella, J. (2017) Study of the training needs of industrial companies in the Barcelona area and proposal of training courses and methodologies to enhance further competitiveness. Procedia Manuf. v. 13, p. 1426-1431, 2017.

[22] Puncreobutr, V. (2016) Education 4.0: New Challenge of Learning. In St. Theresa Journal of Humanities and Social Sciences, v. 2 (2), pp. 92-97.

[23] Scaico, P. D.; Corlett, E. F.; Paiva, L. F.; Raposo, E. H. S.; Alencar, H.; (2012) Relato da Utilização de uma Metodologia de Trabalho para o Ensino de Ciência da Computação no Ensino Médio. In Anais Workshop de Informática na Escola, Rio de Janeiro, Brasil.

[24] Scheer, W. (2015) Hochschule 4.0 [Online]. Available: https://www.gategermany.de/fileadmin/dokumente/angebote/Kongresse/MarketingKongress/2015/Web_Scheer_Whitepaper_Nr_8_Hochschule_4_0.pdf, accessed 21.12.18.

[25] Strauss, A., Corbin, J. (2008) Basics of Qualitative Research. Techniques and Procedures for Developing Grounded Theory. Sage Pub, pp. 400, 2008.

[26] Wohlin, C., Runeson, P., Höst, M., Ohlsson, M., Regnell, B., Wessl. A. (2000) Experimentation in software engineering: an introduction". KluwermAcademic Publishers, pp. 236. 